Review / Meta-analyses

\title{
Burnout in medical students before residency: A systematic review and meta-analysis
}

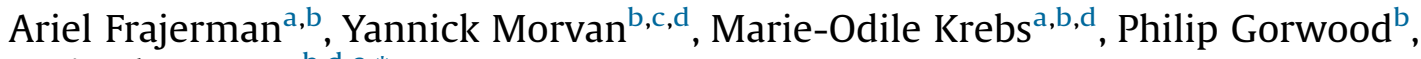 \\ Boris Chaumette ${ }^{\mathrm{b}, \mathrm{d}, \mathrm{e}, *}$ \\ a SHU - Centre Hospitalier Sainte Anne, Paris, France \\ ${ }^{\mathrm{b}}$ Inserm U894, Centre de Psychiatrie et Neurosciences, Paris, France \\ ' Département de psychologie, UFR SPSE, laboratoire CLIPSYD, Université Paris Nanterre, Nanterre, France \\ ${ }^{\mathrm{d}}$ CNRS GDR 3557 Institut de psychiatrie, France \\ e Montreal Neurological Institute and Hospital, Department of Neurology and Neurosurgery, McGill University, Montreal, Quebec, Canada
}

\section{A R T I C L E I N F O}

\section{Article history:}

Received 27 April 2018

Received in revised form 15 August 2018

Accepted 31 August 2018

Available online 29 October 2018

\section{Keywords:}

Depression

Exhaustion

Anxiety

Undergraduate

Professional

Burnout

\begin{abstract}
A B S T R A C T
Background: Applying the concept of burnout to medical students before residency is relatively recent. Its estimated prevalence varies significantly between studies. Our objective was to estimate the prevalence of burnout in medical students worldwide.

Methods: We systematically searched Medline for English-language articles published between January 1, 2010 and December 31, 2017. We selected all the original studies about the prevalence of burnout in medical students before residency, using validated questionnaires for burnout. Statistical analyses were conducted using the OpenMetaAnalyst software.

Results: Prevalence of current burnout was extracted from 24 studies encompassing 17,431 medical students. Among them, 8060 suffered from burnout and we estimated the prevalence to be $44.2 \%$ [ $33.4 \%$ $55.0 \%]$. The information about the prevalence of each subset of burnout dimensions was given in nine studies including 7588 students. Current prevalence was estimated to be $40.8 \%$ for 'emotional exhaustion' [32.8\%-48.9\%], 35.1\% [27.2\%-43.0\%] for 'depersonalization' and 27.4\% [20.5\%-34.3\%] for 'personal accomplishment'. There is no significant gender difference in burnout. The prevalence of burnout is slightly different across countries with a higher prevalence in Oceania and the Middle East than in other continents.

Conclusions: The results of this meta-analysis suggest that one student out of two is suffering from burnout, even before residency. Again, our findings highlight the high level of distress in the medical population. These results should encourage the development of preventive strategies.
\end{abstract}

(C) 2018 Elsevier Masson SAS. All rights reserved.

\section{Introduction}

In 1903, a JAMA editorial entitled "Suicides of physicians and the reasons" alerted about suicide among physicians in the United States of America. It noted that "they far exceed the average ratio of suicides in the general population." [1] After more than a century, physicians' suicides remain a major public health issue. A 2004 meta-analysis reported suicide ratio to be $1.41(95 \% \mathrm{CI}=1.21-1.65)$ among male physicians and 2.27 (95\% CI=1.90-2.73) among female physicians [2], compared to the general population. Suicides are multifactorial, but severe mental illnesses account

\footnotetext{
* Corresponding author at: Ludmer Building, 1033 Pine Avenue, H3A 1A1, Montreal, QC, Canada.

E-mail address: boris.chaumette@mcgill.ca (B. Chaumette).
}

for $47 \%-74 \%$ of the population attributable risk of suicide [3]. Better understanding of the contributing factors, such as affective disorders and work-related stress, could help prevent suicide.

Several contributing factors seem to appear early in medical studies. In a meta-analysis [4] of 54 studies and 17,560 subjects, the prevalence of depressive symptoms in residents was estimated to be 28.8\% ( $\mathrm{CI}=25.3-32.5)$. Rotenstein et al. [5] explored medical students before residency and found 167 cross-sectional studies totaling 116,628 individuals and 16 longitudinal studies totaling 5728 individuals from 43 countries. The prevalence of current depression or depressive symptoms was $27.2 \%$ (CI, 24.7-29.9\%) and the prevalence of suicidal ideation was $11.1 \%$ (CI 9.0-13.7\%). The prevalence did not significantly differ between studies of either preclinical or clinical students. Using the CIDI scale [6], a European epidemiological study [7] found a 12-month prevalence of depression in the general population to be $3.9 \%$ (CI 3.6-4.2\%). In the US 
general population, the same scale estimated the 12-month prevalence of a major depressive episode to be 9.3\% among 18-25 and $7.2 \%$ among $26-49$ year-olds [8]. In the student population, a study including totaling 17,348 students from 23 countries estimated the prevalence of current depression (BDI score $>8$ ) to be $19 \%$ in men and $22 \%$ in women [9].

Thus, a reasonable hypothesis is that medical students are more depressed than the general population, even before residency. Such early onset of distress could affect the mental health of physicians. Limited cross-sectional data suggest that the prevalence of psychological distress is higher among more advanced students. One longitudinal study followed medical students as they transitioned from Medical School into residency. It found that those who worry extensively are more likely to develop exhaustion 6-10 months after graduation [10]. Students experiencing psychological distress may be more vulnerable to mental health problems after graduation. Suicide prevention among physicians requires managing early stress during medical studies.

Rotenstein et al. hypothesized that possible causes of current depressive and suicidal symptomatology in medical students likely include stress and anxiety associated with the competitiveness of medical school. Exploring the potentially deleterious impact of medical studies on mental health, Brazeau et al. believe that, before embarking on their studies, medical students experience less burnout (27.3 vs 37.3, $\mathrm{p}<0.001)$ and have fewer depressive symptoms ( 26.2 vs $42.4, \mathrm{p}<0.0001)$ than the general population [11]. The same team reported more symptoms of depression in medical students during their studies and early career than in the general population [12]. Actually, the notion of burnout could partly explain the emergence of depressive and suicidal symptoms. Burnout is a multifaceted work-related construct created by Freudenberger [13]. It was developed for health professions [14] by Maslach et al. in the eighties. Burnout occurs when three categories of symptoms combine - 'Emotional Exhaustion' (EE), 'Depersonalization' (DP), and 'Personal Accomplishment' (PA). Emotional Exhaustion is defined as an extreme fatigue due to continuous exposure to stressors, with the feeling of being drained of emotional resources. Depersonalization occurs when the attitude becomes negative, cold and detached. Gradually, the affected workers disengage from their work, as well as their relations with co-workers, and develop pejorative cynical conceptions. The Personal Accomplishment category refers to a low self-esteem, reflecting both the feeling of being ineffective in the work and not being up for the position.

Though originally developed for medical professions, the burnout syndrome was subsequently extended to all workers. It has been routinely used over the past decade. Still, the fifth edition of the Diagnostic and Statistical Manual of Mental Disorders does not consider burnout a disease. Yet, burnout has been established as a legitimate cause for sick leave in several countries, including Sweden [15]. It has been identified as a factor influencing health status and help-seeking with health services in the 10th edition of the International Classification of Diseases (ICD-10) where burnout is coded Z73.0 and defined as a state of vital exhaustion [16]. The emergence of the burnout concept has led to new studies among physicians, residents, and medical students. Burnout is shown by a continuous measure that can be evaluated by dedicated scales over one year. The Maslach Burnout Inventory (MBI) is the most widely used scale in the world and exists in several versions to suit the populations studied: the original HSS (1981) for health professionals, GS (1996) for the general population and SS (2002) for students [17]. Since the beginning of the 2000's, other scales have appeared: the Oldenburg Burnout Inventory (OLBI) [18] and the Copenhagen Burnout Inventory (CBI) [19]. The MBI is used to classify enduring burnout into low, intermediate, and high levels. To assess an individual's burnout level, the authors recommend comparing his scores to the country's standard cut-off point established in epidemiological studies $[20,21]$. The strength of the MBI lies both in its 30-year-long use and validation - especially in students [17]- in many languages. The CBI is considered very similar to the MBI with construct validity equivalence : one study [22] compared the 3 scales (MBI-SS, CBI-SS and OLBI-SS) and found that the validity related to the construction can be accepted for CBI-SS and MBI-SS but not for OLBI-SS.

Previous reviews, both in residents and in medical students $[23,24]$, have identified the prevalence of burn-out to be between $17.6 \%$ and $82 \%$. This broad range could be explained by the different versions of the MBI assessment and cut-off scales. Moreover, medical studies differ across countries and work environments have been changing. Evolutions have included lower mortality rate, emerging specialties (palliative care, antipain teams, or rehabilitation units), new medical tests and therapies, fewer paramedical staff, hospital beds reduction, and more administrative tasks. New technologies, like smartphones, have also weakened the boundaries between private and professional lives. Thus, our aim is to precisely evaluate the current prevalence of burnout. In this article, we conduct a metaanalysis of published studies and several meta-regressions to identify potential confounding factors. We propose to use the most widely validated scales and to focus on the past eight years for clinical relevance and homogeneity. Thus, living (mobile phones, social networks, or emails), working, and studying (including exams) environments are more homogeneous. We then examine the effects of year, gender, and geographic area.

\section{Material and methods}

\subsection{Data sources}

Two independent investigators ( $\mathrm{AF}$ and $\mathrm{BC}$ ) performed systematic bibliographic Medline searches using the following queries ("burnout, professional"[MAJR] OR ("burnout, professional"[TI] OR "professional burnout"[TI] OR "physical and emotional exhaustion state"[TI] OR "occupation-related stress disorder, nos"[TI])) AND ("students, medical"[MAJR] OR ("students, medical"[TI] OR "medical students"[TI] OR "student, medical"[TI] OR "medical student"[TI]). The search was conducted in January 2018. The bibliography of the selected articles was subsequently screened to identify other studies which had not been identified during the initial search.

\subsection{Study selection}

We only retained the studies which reported on the burnout of medical students before residency (undergraduate students) and included prevalence data in this specific population. Studies including students in other medical fields (as nurses) were removed. The language of the publication was restricted to English, because we needed to deeply understand the methodology used. Based on our aim to assess the recent evolution of students' mental health, we only retained the articles published between January 1 , 2010 and December 31, 2017. Burnout had to have been assessed using one validated scale (MBI or CBI). The flow-chart is shown in Supplementary Fig. 1. Excluded articles and the reasons for exclusion are given in Supplementary Table 1.

\subsection{Data extraction}

We systematically extracted and recorded data about diagnostic assessment, sample size, sample characteristics (especially about gender), country, year of publication, average burnout prevalence as specified by the authors, and response rate. 


\subsection{Statistical analyses}

To conduct the meta-analysis, we applied the DerSimonianLaird method and used the OpenMetaAnalyst software [25]. As we expected great between-study heterogeneity, we elected to use a continuous random-effects method. Then, data were split according to continents and clinical scales to conduct subgroup metaanalyses. A meta-regression was performed to detect a gender impact or an effect of response rate. Biases and outliers were detected using sensitivity analysis (leave-one-out method). A funnel plot was constructed using the metaphor R package [26], and a bilateral alpha-risk of 0.05 was assumed.

\section{Results}

3.1. Prevalence of current burnout in medical students between 2010 and 2018

The systematic review found 24 studies [11,12,27-48] totaling 17,431 medical students worldwide (Table 1). Among them, 8060 suffered from burnout. We estimated its prevalence to be $44.2 \%$ [33.4\%-55.0\%] (Fig. 1). Information about the prevalence of each subset of symptoms was given in nine studies including 7588 students. The prevalence of 'emotional exhaustion,' 'depersonalization,' and 'personal accomplishment' was estimated to be $40.8 \%$ [32.8\%-48.9\%], 35.1\% [27.2\%-43.0\%], and 27.4\% [20.5\%-34.3\%] respectively (Supplementary Fig. 2).

\subsection{Factors affecting the prevalence of current burnout}

As great heterogeneity was detected ( $\mathrm{I} 2=99.63$ and $\mathrm{p}<0.001)$, we tested for different sampling biases. Leave-one-out analysis was conducted to detect any publication bias (Supplementary Fig. 3). A funnel plot was constructed (Supplementary Fig. 4). One study lay outside the funnel plot, with burnout prevalence estimated to be $100 \%$ [49]. This study was excluded from the meta-regression and subgroup analyses. Twenty studies used the Maslach Burnout Inventory (MBI) and three used the Copenhagen Burnout Inventory
(CBI). Though CBI total scores were slightly higher, the difference was not significant ( $p=0.45)$ (Supplementary Fig. 5).

As medical studies and mental health differ across countries, we searched for geographic disparities in prevalence. Countries were grouped into continental regions: North America, Asia, Europe, Oceania, the Middle East, and South \& Central America. No studies were available for Africa. Prevalence in each continent is given in Fig. 2. Oceania and Middle East students exhibited the highest prevalence of burnout whereas students from South \& Central America exhibited the lowest prevalence. The prevalence of burnout in the Middle East and Oceania significantly differed from Europe $\left(\mathrm{p}=0.022 ; \mathrm{p}<10^{-3}\right.$ respectively) and South \& Central America ( $\mathrm{p}=0.024 ; \mathrm{p}=0.03$ respectively).

We detected no effect of gender on the prevalence of burnout (Omnibus p-value $=0.07$ - Fig. 3 ). The result of the meta-regression is shown in Fig. 3. The effect of the publication year was not significant (Omnibus p-value=0.93; Supplementary Fig. 6). Effect of the response rates was also not significant (Omnibus pvalue $=0.29-$ Supplementary Fig. 7).

\section{Discussion}

The present meta-analysis found the prevalence of current burnout to be $44.2 \%$ [33.4-55.0] among medical students. Several factors have been examined. Notably, we found no significant difference in prevalence between men and women. There were no longitudinal changes in prevalence during the past eight years. Such findings may result from insufficient statistical power and from the limited eight-year time span. However, we should keep in mind that attention to burnout among medical students has only relatively recently led to measuring and evaluating. Indeed, in their 2006 systematic review, Dyrbye et al. [50] found no study about burnout among medical students in North America. Furthermore, the publication date imperfectly reflects the time of assessment, a parameter that is not always mentioned in the ensuing articles and therefore could not be included in the meta-regression. More longitudinal studies are needed to address the question of the gradual change of prevalence.

Table 1

Studies of burnout in medical students.

\begin{tabular}{|c|c|c|c|c|c|c|}
\hline Authors & Date & Journal & Country & Scale & $\begin{array}{l}\text { Gender } \\
\text { (\% of male students) }\end{array}$ & $\begin{array}{l}\text { Response rate } \\
\text { (\% of respondents) }\end{array}$ \\
\hline Al-Alawi et al. & 2017 & Archives of Environmental \& Occupational Health & Oman & MBI & 27.60 & 98.00 \\
\hline Almalki et al. & 2017 & Int J Med Educ & Saudi Arabia & MBI & 67.50 & 81.40 \\
\hline Almeida et al. & 2016 & Arch Clin Psychiatry & Brazil & MBI & 41.10 & 72.70 \\
\hline Asencio-López et al. & 2016 & Medwave & Mexico & MBI & 52.90 & 74.13 \\
\hline Brazeau and al. & 2014 & Academic Medicine & USA & MBI & 54.30 & 62.00 \\
\hline Cecil et al. & 2014 & Medical Education Online & UK & MBI & 34.80 & 13.50 \\
\hline Cook and al. & 2014 & Academic Medicine & USA & MBI & 54.00 & 58.80 \\
\hline Costa et al. & 2012 & CLINICS & Brazil & MBI & 50.40 & 69.10 \\
\hline Dewitt et al. & 2016 & Medical Education & Australia & CBI & 44.30 & 31.00 \\
\hline Dyrbye et al. & 2010 & JAMA & USA & MBI & 51.40 & 61.00 \\
\hline Dyrbye et al. & 2010 & Academic Medicine & USA & MBI & 51.60 & 61.00 \\
\hline Dyrbye et al. & 2014 & Academic Medicine & USA & MBI & 45.10 & 35.20 \\
\hline Dyrbye et al. & 2015 & Academic Medicine & USA & MBI & 50.90 & 35.60 \\
\hline Enoch et al. & 2013 & MEDICAL EDUCATION & USA & MBI & 54.00 & 88.00 \\
\hline Fares et al. & 2015 & Journal of Epidemiology and Global Health & Lebanon & MBI & 53.30 & NA \\
\hline Galan et al. & 2011 & Int Arch Occup Environ Health & Spain & MBI & 30.00 & 60.40 \\
\hline Lyndon et al. & 2017 & Perspect Med Educ & New Zealand & CBI & 44.00 & 47.00 \\
\hline Mazurkiewicz et al. & 2012 & Psychology, Health \& Medicine & Israel & MBI & 43.00 & 70.00 \\
\hline Muzafar et al. & 2015 & Cureus & Pakistan & CBI & 42.50 & NA \\
\hline Popa-Velea et al. & 2017 & Int. J. Environ. Res. Public Health & Romania & MBI & 31.40 & 74.80 \\
\hline Seo et al. & 2015 & Psychiatry Investig & South Korea & MBI & 53.60 & 82.20 \\
\hline Van Venrooij et al. & 2015 & Int J Adolesc Med Health & Netherland & MBI & 24.50 & 33.00 \\
\hline Wolf and Rosenstock & 2017 & Acad Psychiatry & USA & MBI & NA & 28.70 \\
\hline Youssef & 2016 & Acad Psychiatry & Caribbean islands & MBI & 33.00 & 85.00 \\
\hline
\end{tabular}

MBI: Maslach Burnout Inventory - CBI: Copenhagen Burnout Inventory - NA: not available. 
Studies

Al-Alawi et al 2017

Almalki et al 2017

Almeida et al 2016

Asencio-López et al 2016

Brazeau and al 2014

Cecil et al 2014

Cook and al 2014

Costa et al 2012

Dewitt et al 2016

Dyrbye et al 2010

Dyrbye et al (b) 2010

Dyrbye et al (c) 2014

Dyrbye et al (d) 2015

Enoch et al 2013

Fares et al 2015

Galan et al 2011

Lyndon et al 2017

Mazurkiewicz et al 2012

Muzafar et al 2015

Popa-Velea et al 2017

Seo et al 2015

Van Venrooij et al 2015

Wolf and Rosenstock 2017

Youssef 2016

Overall $\left(\left.\right|^{\wedge} 2=99.63 \%, P<0.001\right) \quad 0.442 \quad(0.334,0.550)$
Estimate (95\% C.I.) Affected/Total

$0.074(0.054,0.094) \quad 49 / 662$

$0.618(0.558,0.679) \quad 154 / 249$

$0.149(0.113,0.185) \quad 56 / 376$

$0.993(0.974,1.000) \quad 72 / 72$

$0.273(0.237,0.309) \quad 159 / 582$

$0.266(0.220,0.312) \quad 95 / 357$

$0.340(0.301,0.380) \quad 192 / 564$

$0.103(0.072,0.134) \quad 38 / 369$

$0.510(0.473,0.548) \quad 351 / 688$

$0.528(0.509,0.547) \quad 1416 / 2682$

$0.473(0.452,0.494) \quad 1063 / 2248$

$0.559(0.544,0.574) \quad 2460 / 4400$

$0.527(0.494,0.560) \quad 460 / 873$

$0.372(0.294,0.451) \quad 54 / 145$

$0.752(0.686,0.817) \quad 124 / 165$

$0.226(0.176,0.276) \quad 61 / 270$

$0.611(0.557,0.665) \quad 193 / 316$

$0.709(0.613,0.805) \quad 61 / 86$

$0.470(0.435,0.505) \quad 365 / 777$

$0.151(0.110,0.191) \quad 45 / 299$

$0.338(0.281,0.396) \quad 89 / 263$

$0.460(0.413,0.507) \quad 199 / 433$

$0.586(0.513,0.659) \quad 102 / 174$

$0.530(0.480,0.580) \quad 202 / 381$

$8060 / 17431$

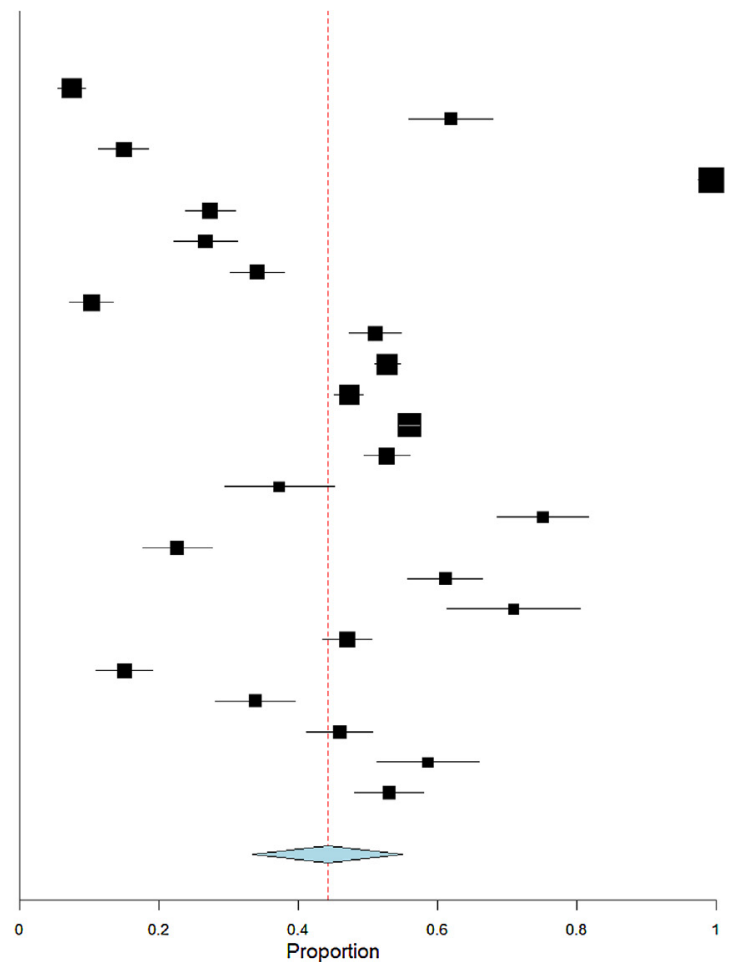

Fig. 1. Forest plot showing the prevalence of burnout in medical students.

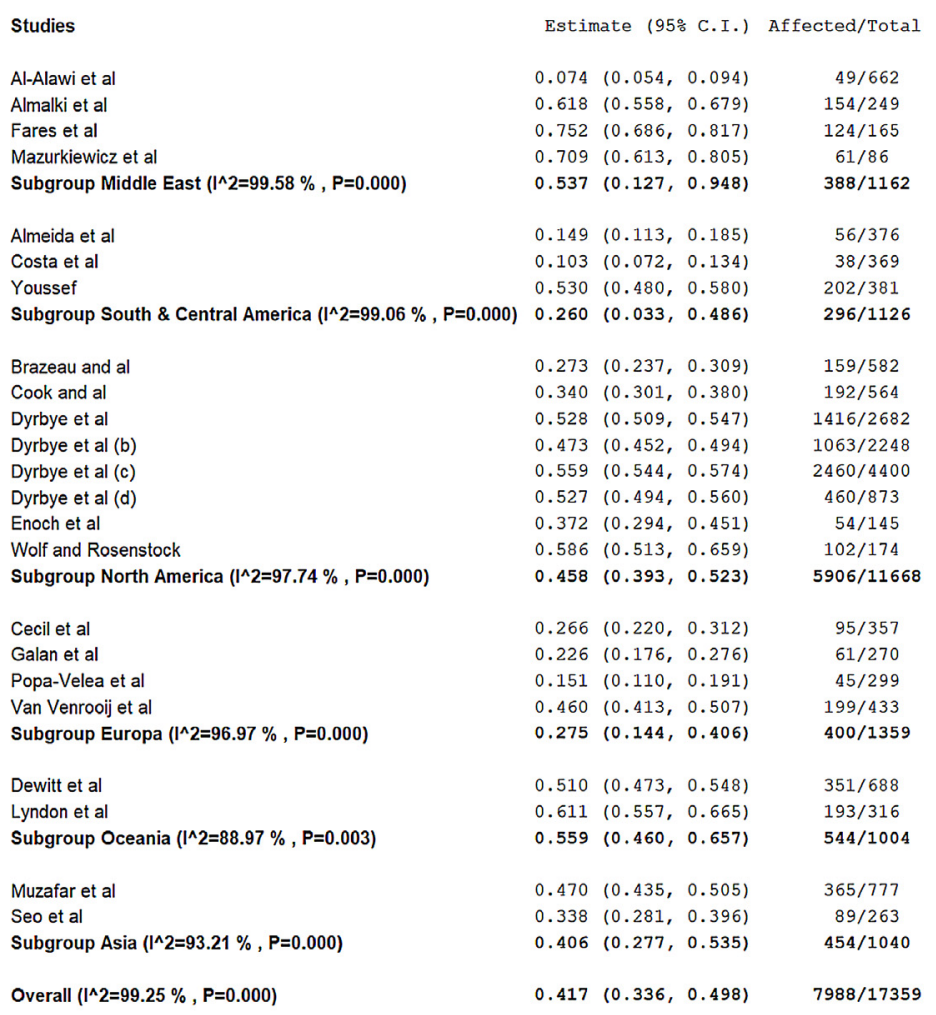

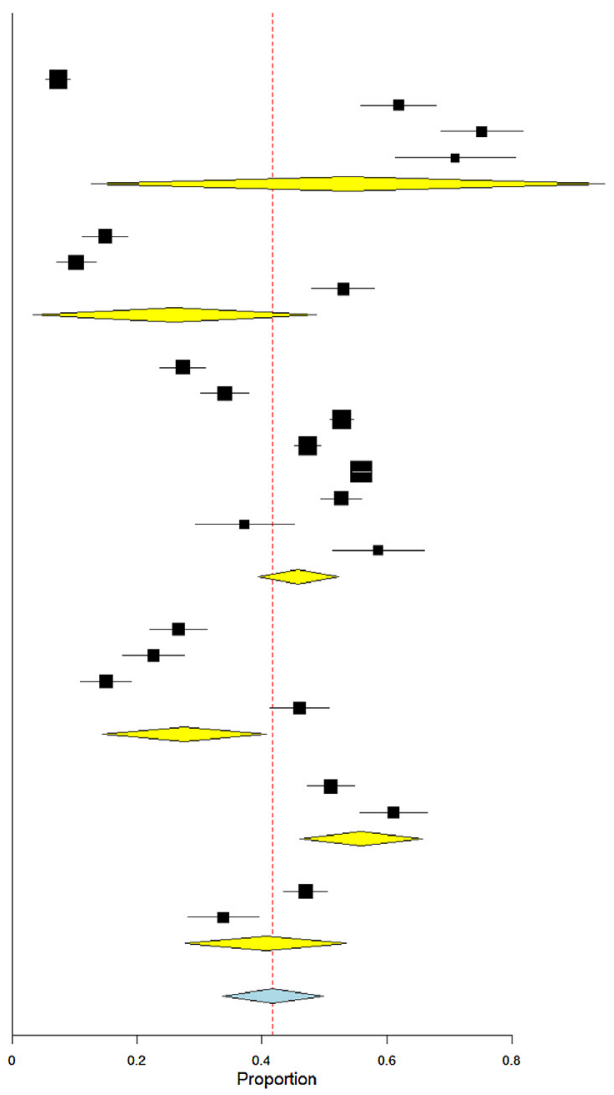

Fig. 2. Forest plot showing the continent-based prevalence of burnout in medical students. 


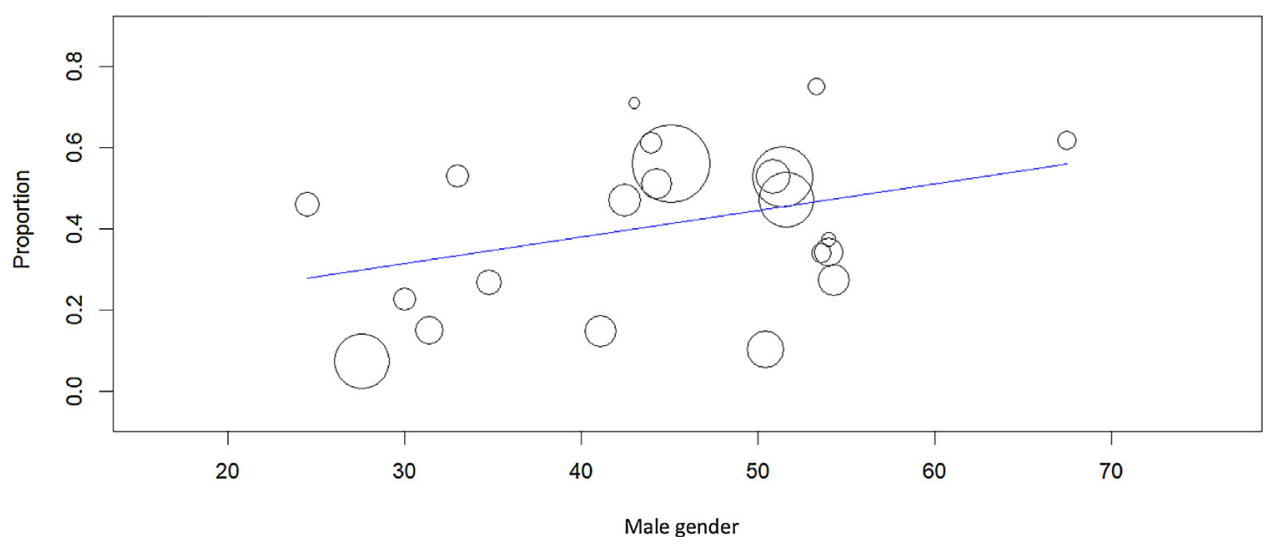

Fig. 3. Gender-based meta-regression of burnout in medical students.

Finally, we found that geographic localization significantly affected the prevalence of current burnout. Oceania and, in a less extend, the Middle East, have higher levels of current burnout compared to South \& Central America and Europe. Burnout does not occur as the result of a single cause. The main factors contributing to burnout in medical students include the curriculum with stress related to the competition, the exams or the cost of the studies, as well as hospital conditions with workload, exposure to patients' suffering and death, style of management. Other external reasons could explain the variations between countries, notably the living conditions (war, terrorism, poverty,...). Additionally, we decided to group all the countries from Europe, despite a certain economic and politic heterogeneity between East and West European countries. However, since the Bologna agreements, a diploma acquired in one of the countries of the European union is valid throughout the union. Moreover, with the Erasmus program, there are many students exchange between the different European countries.

Our estimate is consistent with Ishak et al.'s estimate from their systematic review - between 45 and $71 \%$. It is also consistent with Prins et al.'s [51] results in residents - 18 to $82 \%$ - and with Fares et al.'s [24] findings in preclinical medical students -25 to $75 \%$. The high prevalence of current burnout in medical students is not surprising and highlights medical students' high level of suffering before embarking on their residency. Burnout is related to depression and anxiety [52] and could explain the high prevalence of these psychiatric symptoms in medical students [5]. It has been suggested that burnout may be a risk factor for depression and anxiety in the following years. Several studies have pointed that burnout seems to predict and increase depression [53-55]. Others have found that depression predicts burnout $[56,57]$. In brief, it has been proposed that burnout and depression were reciprocally related $[58,59]$. Burnout has also been associated with anxiety [6062], tobacco and alcohol consumption, antidepressants use, and suicidal thoughts $[63,64]$. As stated in the report by the French Academy of Medicine, burnout may appear before the development of a psychiatric disorder, including anxiety or depression [65].

Consequently, comorbidity between depression or suicidal thoughts in medical students and burnout implies that prevention of mental health disorders should target students' working and studying environments. The competitiveness of medical school has been questioned [5]. However, though forms of training and selection differ around the world, the relative stability of world prevalence contradicts this hypothesis. Other factors have been proposed to explain the high prevalence of current burnout, such as quantitative work overload, conflicting levels of dependency, the balance between responsibility and autonomy, young age, or the confrontation with suffering and dying patients. A recent
French report from Dr Donata Marra [66] has proposed some suggestions to address this issue. The first step is to take into consideration the students and to recognize their emotions and suffering; in consequence, structures providing psychological support and help for orientation (choice of medical specialty) and warranting confidentiality should be available to each student in all faculties. A second step would be to reduce the workload and to adapt the modalities of evaluation with reducing the importance of ranking. Several studies have found a correlation between the number of hours worked and burnout. Reducing the workload has been associated with a decrease in burnout prevalence [67-69], an effect depending on the medical specialties [70]. The third recommendation provided by the Marra's report is to train supervisors for teaching and management as well as for recognizing the distress symptoms of students. Finally, specific interventions should be considered to help students suffering from burnout symptoms. A meta-analysis of interventions for burnout in medical doctors has been published [71]. It comprised 15 randomized trials of interventions to prevent burnout. Though there are not as many studies into medical students, interest has been growing [72] and some attempts should be reported. Changes in the management, practices, and conceptions of students' wellbeing have been ongoing, mostly in North America. For instance, since 2011, Saint Louis University School of Medicine has been pursuing a multipronged strategy to address these issues in the preclinical years. These efforts have successfully decreased the level of depression and anxiety symptoms in students [73]. For medical residents, several studies have shown that limiting weekly working hours reduced the risk of burnout [67-74]. A recent systematic review [75] found 28 articles describing empirically evaluated interventions to improve medical students' emotional well-being. They included randomization focused on pass/fail grading systems ( 3 articles), mental health programs $(n=4)$, mindbody skill programs $(n=7)$, curriculum structure $(n=3)$, multicomponent program reform $(n=5)$, wellness programs $(n=4)$, and advising/mentoring programs $(n=3)$. An essential component of these interventions is the ongoing measurement of mental health outcomes across all four years of the curriculum. Efforts directed at changing the educational and clinical environments are also needed to reduce unnecessary stressors and create more positive settings for learning and clinical care. Peer support and companionship appear to be protective. Some students report humiliations and bullying in the hospital [76]. It has been demonstrated that supervisors' types of leadership play a critical role in the wellbeing of the physicians they supervise [77]. Improvement of the relationships between students and supervisors is attainable.

Destigmatizing psychologic distress, promoting prevention, and recognizing the symptoms are crucial factors to encourage 
medical students to seek help. Thus, the growing number of studies over the past decade has increased professionals' and students' burnout awareness. Early interventions targeting students' suffering, should be viewed as a mean to prevent the development of any future psychiatric disorder. In addition, improving the well-being of medical students is also necessary to provide better care to patients, as a recent meta-analysis [78] has found a clear impact of current burnout on work efficiency.

Our meta-analysis has some limitations. First, our methodology to review only articles written in English may have excluded some relevant articles from non-English speaking countries. Additionally, burnout remains an entity to better define across countries. Initially defined as a continuum [79], burnout is nowadays refers as a dichotomous entity but cut-off to define it is variable. Schaufeli recommended to employ "only nation-specific and clinically derived cut-off points" [80]. Whereas it has been recommended to adapt the cut off for burnout based on the continuous score provided by the scales in some countries [8082], the cross national validity has been demonstrated [83-87]. For example, Popa-Velea et al [45] considered "the criteria of burnout to be met if the participants had a score above 30 on the EE scale and if at least one of the scores of the other two dimensions were above the recommended cut-off points (DP: 11; PA: 35)". Some included studies did not report their cut off for the 3 subscales of the MBI, so we cannot estimate their reliability [80]. On the 24 studies of the meta-analysis, 3 used CBI scale and $21 \mathrm{MBI}$ scale. However, we provided a funnel plot to estimate this bias and decided to exclude a study [57] with obvious deviation from the others.

Another limitation is that the scales measuring burnout have been designed for enduring state. Consequently, they are relatively insensitive to minor fluctuations. Finally, the choice of a limited and short period may have decreased the number of studies included in our meta-analysis but warranted a better homogeneity. The working conditions of the medical student are timedependent. Last decade has been associated with advances in medical science, development of new teaching and evaluation methods. Since 2010, new ways of communication resulting in an imperative to be always reachable have favored stress during the period of rest. In several private compagnies, the "right to disconnect" has been warranted to alleviate workers to disconnect from work and primarily not to engage in work-related electronic communications such as e-mails or messages during non-work hours but this is not the case in medicine. External conditions have also contributed to changes in hospital environment. The 2008 financial crisis had global impacts on health systems: reduction of budget and staff [88], degradation of work conditions for caregivers [89].

The present meta-analysis shows that the current prevalence of burnout among medical students is important. Nearly one medical student out of two suffers from burnout. Awareness of mental health issues during medical studies and before residency is still in its infancy. However, this is the first step towards developing interventional trials to decrease the prevalence of burnout. Some attempts have already been tested, mainly in North America, with positive results. These methods should be evaluated and extended to other countries, including European countries and countries with higher prevalence of burnout.

\section{Funding}

No current external funding sources for this study.

\section{Declaration of interest}

The authors declare no conflict of interest related to this study.

\section{Acknowledgements}

We would like to thank Pascale Eisenberger from the Centre de Langues in Université Paris Descartes (France) for the English language editing. Boris Chaumette receives a postdoctoral fellowship from the Healthy Brains for Healthy Lives project (Talent program).

\section{Appendix A. Supplementary data}

Supplementary material related to this article can be found, in the online version, at doi:https://doi.org/10.1016/j.eurpsy.2018.08.006.

\section{References}

[1] Suicides of physicians and the reasons. J Am Med Assoc 1903;XLI:263-4.

[2] Schernhammer E.S., Colditz GA. Suicide rates among physicians: a quantitative and gender assessment (meta-analysis). Am J Psychiatry 2004;161:2295-302.

[3] Swanson JW, Bonnie RJ, Appelbaum PS. Getting serious about reducing suicide: more 'How' and less 'Why'. JAMA 2015;314:2229-30.

[4] Mata DA, et al. Prevalence of Depression and Depressive Symptoms Among Resident Physicians: A Systematic Review and Meta-analysis. JAMA 2015;314:2373.

[5] Rotenstein LS, et al. Prevalence of Depression, Depressive Symptoms, and Suicidal Ideation Among Medical Students: A Systematic Review and MetaAnalysis. JAMA 2016;316:2214-36.

[6] Kessler RC, Ustün TB. The world mental health (WMH) survey initiative version of the world health organization (WHO) composite international diagnostic interview (CIDI). Int J Methods Psychiatr Res 2004;13:93-121.

[7] The ESEMeD/MHEDEA 2000 Investigators, et al. Prevalence of mental disorders in Europe: results from the European Study of the Epidemiology of Mental Disorders (ESEMeD) project. Acta Psychiatr Scand 2004:109:21-7.

[8] Kessler RC, et al. The Epidemiology of Major Depressive Disorder: Results From the National Comorbidity Survey Replication (NCS-R). JAMA 2003;289:3095-105.

[9] Steptoe A, Tsuda A, Tanaka Y, Wardle J. Depressive symptoms, socio-economic background, sense of control, and cultural factors in university students from 23 countries. Int J Behav Med 2007; 14:97-107.

[10] Dahlin M, Fjell J, Runeson B. Factors at medical school and work related to exhaustion among physicians in their first postgraduate year. Nord J Psychiatry 2010;64:402-8.

[11] Brazeau CMLR, et al. Distress among matriculating medical students relative to the general population. Acad Med J Assoc Am Med Coll 2014;89:1520-5.

[12] Dyrbye LN, et al. Burnout among U.S. Medical students, residents, and early career physicians relative to the general U.S. Population. Acad Med J Assoc Am Med Coll 2014;89:443-51.

[13] Freudenberger HJ. Staff burn-out. J Soc Issues 1974;30:159-65.

[14] Maslach C, Jackson SE. The measurement of experienced burnout. J Organ Behav 1981;2:99-113.

[15] Friberg T. Burnout: from popular culture to psychiatric diagnosis in Sweden. Cult Med Psychiatry 2009;33:538-58.

[16] ICD-10-CM Code Z73.0 - Burn-out. Available at: https://icd.codes/icd10cm/ Z730. (Accessed 27 November 2017).

[17] Schaufeli WB, Martinez IM, Pinto AM, Salanova M, Bakker AB. Burnout and engagement in university students: a cross-national study. J Cross-Cult Psychol 2002;33:464-81.

[18] Demerouti E, Bakker AB, Vardakou I, Kantas A. The convergent validity of two burnout instruments: A multitrait-multimethod analysis. Eur J Psychol Assess 2003; $19: 12$.

[19] Kristensen TS, Borritz M, Villadsen E, Christensen KB. The Copenhagen Burnout Inventory: a new tool for the assessment of burnout. Work Stress 2005;19:192-207.

[20] Maslach C, Jackson SE, Schwab RL. Maslach burnout inventory: manual. Consulting Psychologists Press; 1986.

[21] Maslach C, Jackson S, Leiter M. The maslach burnout inventory manual 1997;3:.

[22] Maroco J, Campos JADB. Defining the student burnout construct: a structural analysis from three burnout inventories. Psychol Rep 2012;111:814-30.

[23] Ishak W, et al. Burnout in medical students: a systematic review. Clin Teach 2013; 10:242-5.

[24] Fares J, Al Tabosh H, Saadeddin Z, El Mouhayyar C, et al. Burnout and coping strategies in preclinical medical students. North Am J Med Sci 2016;8:75-81.

[25] Wallace BC, Schmid CH, Lau J, Trikalinos TA. Meta-Analyst: software for metaanalysis of binary, continuous and diagnostic data. BMC Med Res Methodol 2009;9:80.

[26] Viechtbauer W. Conducting Meta-Analyses in R with the metafor Package. J Stat Softw 2010;36:

[27] Cecil J, McHale C, Hart J, Laidlaw A. Behaviour and burnout in medical students. Med Educ Online 2014;19:25209.

[28] Cook AF, Arora VM, Rasinski KA, Curlin FA, Yoon JD. The prevalence of medical student mistreatment and its association with burnout. Acad Med J Assoc Am Med Coll 2014:89:749-54.

[29] Dyrbye LN, et al. Relationship between burnout and professional conduct and attitudes among US medical students. JAMA 2010;304:1173-80. 
[30] Dyrbye LN, et al. Patterns of distress in US medical students. Med Teach 2011;33:834-9.

[31] Enoch L, Chibnall JT, Schindler DL, Slavin SJ. Association of medical student burnout with residency specialty choice. Med Educ 2013:47:173-81.

[32] Fares J, et al. Extracurricular activities associated with stress and burnout in preclinical medical students. J Epidemiol Glob Health 2016;6:177-85.

[33] Mazurkiewicz R, Korenstein D, Fallar R, Ripp J. The prevalence and correlations of medical student burnout in the pre-clinical years: a cross-sectional study. Psychol Health Med 2012;17:188-95.

[34] de Costa EFO, Santos SA, et al. Burnout Syndrome and associated factors among medical stu dents: a cross-sectional study. Clin São Paulo Braz. 2012;67:573-80.

[35] van Venrooij LT, Barnhoorn PC, Giltay EJ, van Noorden MS. Burnout, depression and anxiety in preclinical medical students: a cross-sectional survey. Int J Adolesc Med Health 2015, doi:http://dx.doi.org/10.1515/ijamh-2015-0077.

[36] Galán F, Sanmartín A, Polo J, Giner L. Burnout risk in medical students in Spain using the Maslach Burnout Inventory-Student Survey. Int Arch Occup Environ Health 2011:84:453-9.

[37] Muzafar Y, et al. Burnout and its associated factors in medical students of Lahore, Pakistan. Cureus 2015;7:e390.

[38] Seo J-H, Kim HJ, Kim B-J, Lee S-J, Bae H-O. Educational and relational stressors associated with burnout in korean medical students. Psychiatry Investig 2015;12:451-8.

[39] Almalki SA, Almojali AI, Alothman AS, Masuadi EM, Alaqeel MK. Burnout and its association with extracurricular activities among medical students in Saudi Arabia. Int J Med Educ 2017;8:144-50.

[40] de Almeida GC, et al. The prevalence of burnout syndrome in medical students. Arch Clin Psychiatry São Paulo 2016;43:6-10.

[41] Asencio-López L, et al. Burnout syndrome in first to sixth-year medical students at a private university in the north of Mexico: descriptive crosssectional study. Medwave 2016;16:e6432.

[42] DeWitt D, Canny BJ, Nitzberg M, Choudri J, Porter S. Medical student satisfaction, coping and burnout in direct-entry versus graduate-entry programmes. Med Educ 2016;50:637-45.

[43] Dyrbye LN, et al. The Impact of Stigma and Personal Experiences on the HelpSeeking Behaviors of Medical Students With Burnout. Acad Med J Assoc Am Med Coll 2015;90:961-9.

[44] Lyndon MP, et al. Burnout, quality of life, motivation, and academic achievement among medical students: a person-oriented approach. Perspect Med Educ 2017;6:108-14.

[45] Popa-Velea O, Diaconescu L, Mihăilescu A, Jidveian Popescu M, et al. Burnout and its relationships with Alexithymia, stress, and social support among romanian medical students: a cross-sectional study. Int J Environ Res Public Health 2017; 14 :

[46] Wolf MR, Rosenstock JB. Inadequate sleep and exercise associated with burnout and depression among medical students. Acad Psychiatry J Am Assoc Dir Psychiatr Resid Train Assoc Acad Psychiatry 2017;41:174-9.

[47] Youssef FF. Medical student stress, burnout and depression in Trinidad and Tobago. Acad Psychiatry J Am Assoc Dir Psychiatr Resid Train Assoc Acad Psychiatry 2016;40:69-75.

[48] Al-Alawi M, et al. Prevalence and determinants of burnout Syndrome and Depression among medical students at Sultan Qaboos University: A crosssectional analytical study from Oman. Arch Environ Occup Health 2017;1-10:, doi:http://dx.doi.org/10.1080/19338244.2017.1400941.

[49] Asencio-López L, et al. Burnout syndrome in first to sixth-year medical students at a private university in the north of Mexico: descriptive crosssectional study. Medwave 2016;16:

[50] Dyrbye LN, Thomas MR, Shanafelt TD. Systematic review of depression, anxiety, and other indicators of psychological distress among U.S. And Canadian medical students. Acad Med J Assoc Am Med Coll 2006;81:354-73.

[51] Prins JT, et al. Burnout in medical residents: a review. Med Educ 2007;41:788 800.

[52] Bianchi R, Schonfeld IS, Laurent E. Burnout-depression overlap: a review. Clin Psychol Rev 2015;36:28-41.

[53] Armon G, Melamed S, Toker S, Berliner S, Shapira I. Joint effect of chronic medical illness and burnout on depressive symptoms among employed adults. Health Psychol Off J Div Health Psychol Am Psychol Assoc 2014;33:264-72.

[54] Hakanen JJ, Schaufeli WB. Do burnout and work engagement predict depressive symptoms and life satisfaction? A three-wave seven-year prospective study. J Affect Disord 2012;141:415-24.

[55] Shin H, Noh H, Jang Y, Park YM, Lee SM. A longitudinal examination of the relationship between teacher burnout and depression. J Employ Couns 2013;50:124-37.

[56] Campbell J, Prochazka AV, Yamashita T, Gopal R. Predictors of persistent burnout in internal medicine residents: a prospective cohort study. Acad Med J Assoc Am Med Coll 2010;85:1630-4.

[57] Salmela-Aro K, Aunola K, Nurmi J-E. Trajectories of depressive symptoms during emerging adulthood: antecedents and consequences. Eur J Dev Psychol 2008;5:439-65.

[58] Salmela-Aro K, Savolainen H, Holopainen L. Depressive symptoms and school burnout during adolescence: evidence from two cross-lagged longitudinal studies. J Youth Adolesc 2009;38:1316-27.

[59] Toker S, Biron M. Job burnout and depression: unraveling their temporal relationship and considering the role of physical activity. J Appl Psychol 2012;97:699-710.
[60] Molina-Canales G, Le Barbier M, Brunel S, Lasfargues G. Épuisement professionnel : étude descriptive de cas recensés dans le Réseau national de vigilance et de prévention des pathologies professionnelles. Arch Mal Prof Environ 2016:77:440.

[61] Toker S, Shirom A, Shapira I, Berliner S, Melamed S. The association between burnout, depression, anxiety, and inflammation biomarkers: C-reactive protein and fibrinogen in men and women. J Occup Health Psychol 2005;10:344-62.

[62] Pereira-Lima K, Loureiro SR. Burnout, anxiety, depression, and social skills in medical residents. Psychol Health Med 2015;20:353-62.

[63] Soler JK, et al. Burnout in European family doctors: the EGPRN study. Fam Pract 2008;25:245-65.

[64] Galam E, Komly V, Le Tourneur A, Jund J. Burnout among French GPs in training: a cross-sectional study. Br J Gen Pract J R Coll Gen Pract 2013;63: e217-24.

[65] Olie J-P, Legeron P. Le burn-out. Académie nationale de médecine; 2016. p. 349-65.

[66] Rapport du Dr Donata Marra sur la Qualité de vie des étudiants en santé. Ministère des Solidarités et de la Santé. 2018. . Available at: http://solidaritessante.gouv.fr/ministere/documentation-et-publications-officielles/rapports/ sante/article/rapport-du-dr-donata-marra-sur-la-qualite-de-vie-desetudiants-en-sante (Accessed 17 June 2018).

[67] Barrack RL, Miller LS, Sotile WM, Sotile MO, Rubash HE. Effect of duty hour standards on burnout among orthopaedic surgery residents. Clin Orthop 2006:449:134-7.

[68] Gopal R, Glasheen JJ, Miyoshi TJ, Prochazka AV. Burnout and Internal Medicine Resident Work-Hour Restrictions. Arch Intern Med 2005;165:2595-600.

[69] Jovanović N, et al. Burnout syndrome among psychiatric trainees in 22 countries: risk increased by long working hours, lack of supervision, and psychiatry not being first career choice. Eur Psychiatry 2016;32:34-41.

[70] Ferrari S, et al. Young and burnt? Italian contribution to the international BurnOut Syndrome Study (BOSS) among residents in psychiatry. Med Lav 2015;106:172-85.

[71] West CP, Dyrbye LN, Erwin PJ, Shanafelt TD. Interventions to prevent and reduce physician burnout: a systematic review and meta-analysis. Lancet 2016;388:2272-81.

[72] Williams D, Tricomi G, Gupta J, Janise A. Efficacy of burnout interventions in the medical education pipeline. Acad Psychiatry J Am Assoc Dir Psychiatr Resid Train Assoc Acad Psychiatry 2014, doi:http://dx.doi.org/10.1007/s40596-0140197-5.

[73] Slavin SJ, Chibnall JT. Finding the why, changing the how: improving the mental health of medical students, residents, and physicians. Acad Med J Assoc Am Med Coll 2016;91:1194-6.

[74] van Vendeloo SN, Brand PLP, Verheyen CCPM. Burnout and quality of life among orthopaedic trainees in a modern educational programme: importance of the learning climate. Bone Jt. J. 2014;96-B:1133-8.

[75] Wasson LT, et al. Association Between Learning Environment Interventions and Medical Student Well-being: A Systematic Review. JAMA 2016;316:223752.

[76] Auslender V. Omerta à l'hôpital: le livre noir des maltraitances faites aux étudiants en santé. Editions Michalon; 2017.

[77] Shanafelt TD, Noseworthy JH. Executive Leadership and Physician Well-being: Nine Organizational Strategies to Promote Engagement and Reduce Burnout. Mayo Clin Proc 2017;92:129-46.

[78] Shoji K, et al. Associations between job burnout and self-efficacy: a metaanalysis. Anxiety Stress Coping 2016;29:367-86.

[79] Schaufeli WB, Leiter MP, Maslach C. Burnout: 35 years of research and practice. Career Dev Int. 2009;14:204-20.

[80] Schaufeli WB, Van Dierendonck D. A cautionary note about the cross-national and clinical validity of cut-off points for the Maslach Burnout Inventory. Psychol Rep 1995;76:1083-90.

[81] Gil-Monte PR, Peiró JM. Un estudio comparativo sobre criterios normativos y diferenciales para el diagnóstico del síndrome de quemarse por el trabajo (burnout) según el MBI-HSS en España. Rev Psicol Trab Las Organ 2000; 16:135-49.

[82] Dion G, Tessier R. Validation de la traduction de l'Inventaire d'épuisement professionnel de Maslach et Jackson. Can J Behav Sci Can Sci Comport 1994;26:210.

[83] Enzmann D, Schaufeli WB, Girault N. The validity of the Maslach Burnout Inventory in three national samples. Health Work. Aids Res Interv Curr Issues Burn Response 1995;131-50.

[84] Schaufeli WB, Janczur B. Burnout among nurses: a polish-dutch comparison. Afr J Cross-cultural Psychol Sport Facil 1994.

[85] Schutte N, Toppinen S, Kalimo R, Schaufeli W. The factorial validity of the Maslach Burnout Inventory-General Survey (MBI-GS) across occupational groups and nations. J Occup Organ Psychol 2000;73:53-66.

[86] Langballe EM, Falkum E, Innstrand ST, Aasland OG. The factorial validity of the Maslach Burnout Inventory-General Survey in representative samples of eight different occupational groups. J Career Assess 2006;14:370-84.

[87] Bakker AB, Le Blanc PM, Schaufeli WB. Burnout contagion among intensive care nurses. J Adv Nurs 2005;51:276-87.

[88] Kalafati M. How Greek healthcare services are affected by the Euro crisis. Emerg Nurse J RCN Accid Emerg Nurs Assoc 2012;20:26-7.

[89] Rachiotis G, et al. Medical supplies shortages and burnout among greek health care workers during economic crisis: a pilot study. Int J Med Sci 2014;11:442-7. 